\title{
Development of multi-isotopic analyses of asteroid samples returned by the Hayabusa2 mission
}

\author{
TETSUYA YOKOYAMA ${ }^{1}$, IKSHU GAUTAM ${ }^{1}$, YUSUKE \\ OHKUMA $^{1}$, TSUYOSHI IIZUKA ${ }^{2}$, MARY F. HORAN ${ }^{3}$ AND \\ RICHARD W. CARLSON ${ }^{3}$ \\ ${ }^{1}$ Tokyo Institute of Technology \\ ${ }^{2}$ The University of Tokyo \\ ${ }^{3}$ Carnegie Institution for Science \\ Presenting Author: tetsuya.yoko@eps.sci.titech.ac.jp
}

The sample return mission Hayabusa2 conducted two sampling sequences that collected surface and sub-surface materials from a C-type asteroid, Ryugu in 2019. The Sample Return Capsule (SRC) containing the collected materials was brought back to the Earth on Dec 6th of 2020. The curation team opened the SRC in a clean chamber at the curation facility of JAXA at Sagamihara, and found black chunks of rocks and dust from Ryugu, of which the total weight reached $>5 \mathrm{~g}$. Although the retrieved sample mass was far more than what was expected at the planning stage (0.1-1 g), each of the initial analysis teams can use only a limited amount of the samples $(<0.1 \mathrm{~g})$ to obtain scientific data that characterize the asteroidal materials. We have developed a technique for a multi-isotopic analysis that uses $\sim 30$ $\mathrm{mg}$ of the Ryugu sample. Two terrestrial basalts (BCR-2, BHVO-2) and two CM chondrites (Murchison, Jbilet Winselwan) were chosen as the analog samples to evaluate the performance of the developed technique. The powdered sample was decomposed by a mixture of $\mathrm{HF}+\mathrm{HNO}_{3}$ in a Teflon vessel. The sample was conditioned with $\mathrm{HBr}$ for the separation of $\mathrm{Pb}$ by anion exchange chromatography (Column-1; AG1-X8). The major element fraction of Column-1 was dried and conditioned with $0.4 \mathrm{M} \mathrm{HCl}-0.5 \mathrm{M} \mathrm{HF}$ for the separation of $\mathrm{Ti}+\mathrm{Zr}+\mathrm{Hf}$, W, and Mo (Column-2; AG1-X8). The major element fraction of Column-2 was dried and conditioned with $6 \mathrm{M} \mathrm{HCl}$ for the separation of $\mathrm{Fe}$ and $\mathrm{U}$ (Column-3; AG1-X8), followed by the separation of $\mathrm{Sr}$ and $\mathrm{Ba}$ (Column-4; Sr-Resin), REEs (Column-5; RE-Resin), Ca (Column-6; DGA-n Resin), and Cr (Column-7; 1:1 mixture of AG50W-X8 and AG50W-X12). Finally, Mg and $\mathrm{Ni}$ were separated using Ni Resin (Column- 8 ). The recovery yields of individual target elements are generally $>90 \%$ during each step of the chromatography. The isotopic compositions of these analog samples, especially for $\mathrm{Cr}$ and $\mathrm{Ti}$, will be reported in the presentation. 